\title{
The efficacy of pulsed-xenon ultraviolet light technology on Candida auris
}

\author{
Caroline Maslo ${ }^{1 * \dagger}\left(\mathbb{D}\right.$, Moira du Plooy ${ }^{2 \dagger}$ and Jennifer Coetzee ${ }^{3 \dagger}$
}

\begin{abstract}
Background: Candida auris is an emerging, often multi-resistant, yeast that causes invasive infections in healthcare settings. Patients may be colonized for months and C. auris has been shown to remain viable on surfaces for at least 14 days. It is widely considered that the environment may be a reservoir for transmission of $C$. auris. The efficacy of pulsed-xenon ultraviolet (PX-UV) mobile devices on C. auris has not been tested previously. In a laboratory setting, we tested efficacy of a PX-UV system on C. auris and C. parapsilosis, another candida known to be responsible for outbreaks in healthcare settings and survive for at least 28 days in the environment.

Methods: Cultures and growth of clinical strains of C. parapsilosis and C. auris was carried out in a broth liquid culture medium at $37^{\circ} \mathrm{C}$ until concentration ranges $10^{5}-10^{6}$ colony-forming units (CFUs) per millilitre were obtained. Glass slides were inoculated with $10 \mu \mathrm{l}$ of C. auris stock culture and allowed to dry. Slides were positioned perpendicular to the floor at a distance of $1.25 \mathrm{~m}$ from the floor. Exposure time were run uninterrupted for 5-, 10- and 15-min cycles at 1- and 2-m distance.

Results: There was a $99.4 \%$ reduction in C. auris CFU after a 5-min cycle at 1-m distance, and $99.6 \%$ reduction after a 10-min cycle at 2-m distance. There was a $98.5 \%$ reduction in C. parapsilosis CFU after a 5-min cycle at 1-m distance, and $95.2 \%$ reduction after a $10-$ min cycle at $2-m$ distance.

Conclusions: The PX-UV mobile device is easy to use and has short cycle times that makes it easier to disinfect all areas outside the room where the patient received care. Further studies are needed in hospital environment, to assess the cumulative impact of repeated sessions.
\end{abstract}

Keywords: Candida spp., Pulsed-xenon ultraviolet light, Disinfection

\section{Background}

Candida auris is an emerging, often multi-resistant, yeast that causes invasive infections in healthcare settings $[1,2]$. C. auris has the ability to cause large healthcare outbreaks $[3,4]$. Patients may be colonized for months $[3,5]$ and $C$. auris has been shown to remain viable on surfaces for at least 14 days [6, 7]. It is widely considered that the environment may be a reservoir for transmission of $C$. auris. The Centre for Disease Control and prevention (CDC) recommends post discharge terminal cleaning and disinfection of patients' rooms and cleaning and disinfection of areas outside the rooms

\footnotetext{
* Correspondence: Caroline.Maslo@netcare.co.za

${ }^{\dagger}$ Caroline Maslo, Moira du Plooy and Jennifer Coetzee contributed equally to this work.

'Department of Quality Leadership, Netcare Hospitals, Johannesburg, South Africa

Full list of author information is available at the end of the article
}

where patients received care [8]. It has been demonstrated that conventional cleaning and disinfection often lacks consistency and that additional disinfection, using non-touch technologies such as hydrogen peroxide vaporisation or germicidal ultraviolet (UV-C) light can further reduce the surface bioburden and transmission of microorganisms [9]. However, a recent publication by Cadnum and colleagues showed a relative resistance of C. auris and other candida species to UV-C and that extended exposure time (20 to $30 \mathrm{~min}$ ) might be needed [10]. In their experiment, Cadnum and colleagues (2018) used a mobile device that emits 254-nm continuous UV-C light. We tested the hypothesis that the pulsedxenon ultraviolet (PX-UV) system that emits broad spectrum UV-C (200-280-nm) in short pulses could reduce the exposure time needed to decrease $C$. auris. As a comparison, we also tested the PX-UV system

(c) The Author(s). 2019 Open Access This article is distributed under the terms of the Creative Commons Attribution 4.0 International License (http://creativecommons.org/licenses/by/4.0/), which permits unrestricted use, distribution, and reproduction in any medium, provided you give appropriate credit to the original author(s) and the source, provide a link to the Creative Commons license, and indicate if changes were made. The Creative Commons Public Domain Dedication waiver (http://creativecommons.org/publicdomain/zero/1.0/) applies to the data made available in this article, unless otherwise stated. 
on C. parapsilosis, another candida known to be responsible for outbreaks in healthcare settings and survive for at least 28 days in the environment [7].

\section{Methods}

Prior cultures and growth of clinical strains of $C$. parapsilosis and C. auris was carried out in a broth liquid culture medium at $37^{\circ} \mathrm{C}$ until concentration ranges $10^{5}-10^{6}$ colony-forming units (CFUs) per millilitre were obtained. Glass slides were inoculated with $10 \mu \mathrm{l}$ of $C$. auris stock culture and allowed to dry.

Slides were positioned perpendicular to the floor at a distance of $1.25 \mathrm{~m}$ from the floor. Exposure time were run uninterrupted for 5-, 10- and 15-min cycles. The experiment was conducted at $1-\mathrm{m}$ distance from the centre of the robot and repeated at a 2-m distance. Tests were conducted in triplicate. Three controls treated in identical conditions were prepared with each organisms. The controls remained covered during the experiment. After exposure, the control and PX-UV exposed slides were incubated in $10 \mathrm{ml}$ phosphate-buffered saline (PBS) and agitated for $30 \mathrm{~s}$ to extract CFUs. Serial dilutions were plated onto Chromagar Candida and incubated at 36*for $48 \mathrm{~h}$. The total viable count was quantified into number of colony forming unit. The percent reduction in the pathogens were calculated in comparison with unexposed control slides. The experiment was repeated for C. parapsilosis.

\section{Results}

The laboratory testing results for $C$. auris are detailed in Table 1, stratified according to cycle time (5, 10 and 15 min) and distance from the centre of the UV light bulb (1 and $2 \mathrm{~m}$ ). At 1-m distance from the PX-UV light bulb, there was a reduction of $99.4 \%$ of $C$. auris CFU observed after a 5-min cycle, while no growth was observed at 10 and $15 \mathrm{~min}$. At 2-m distance from the light bulb, the $C$. auris CFU reduction was $90.2 \%$ after a five minutes cycle, and $99.6 \%$ after a 10 -min cycle. There was no growth at $15 \mathrm{~min}$.At $1-\mathrm{m}$ distance, the average reduction in C. parapsilosis CFU was $98.5 \%$ after a 5 -min cycle. There was no growth at 10 and $15 \mathrm{~min}$. At 2-m distance, the average efficacy was only $15.7 \%$ after a 5 -min cycle while it was $95.2 \%$ after a 10 -min cycle. There was no growth after a 15 -min cycle.

\section{Discussion}

We found that at 1-m distance from the PX-UV light bulb, there was a $99.4 \%$ reduction in $C$. auris after a 5 min cycle and no growth after 10- and 15-min cycles. Similarly, for $C$. parapsilosis there was a $98.5 \%$ reduction after a 5-min cycle and no growth after 10- and 15- min cycles. We found that at 2-m distance, there was a $15.7 \%$ reduction in C. auris after a 5-min cycle, a $95.2 \%$
Table 1 Laboratory testing results for C. auris and C. parapsilosis

\begin{tabular}{|c|c|c|c|}
\hline C.auris & Slide & 1-Meter Distance & 2-Meter Distance \\
\hline Cycle Time & Control & 185 CFU & 185 CFU \\
\hline \multirow[t]{3}{*}{$5 \mathrm{~min}$} & Slide 1 & 1 (99.5\%) & 17 (90.8\%) \\
\hline & Slide 2 & 2 (98.9\%) & 22 (88.1\%) \\
\hline & Slide 3 & No growth & 15 (91.9\%) \\
\hline \multirow[t]{3}{*}{$10 \mathrm{~min}$} & Slide 1 & No growth & No growth \\
\hline & Slide 2 & No growth & $2(98.9 \%)$ \\
\hline & Slide 3 & No growth & No growth \\
\hline \multirow[t]{3}{*}{$15 \mathrm{~min}$} & Slide 1 & No growth & No growth \\
\hline & Slide 2 & No growth & No growth \\
\hline & Slide 3 & No growth & No growth \\
\hline C. parapsilosis & Slide & 1-Meter Distance ${ }^{a}$ & 2-Meter Distance \\
\hline Cycle Time & Controls & $91 \mathrm{CFU}$ & 185 CFU \\
\hline \multirow[t]{3}{*}{$5 \mathrm{~min}$} & 1 & No growth & 74 (18.7\%) \\
\hline & 2 & 1 (98.9\%) & 73 (19.8\%) \\
\hline & 3 & $3(96.7 \%)$ & $83(8.8 \%)$ \\
\hline \multirow[t]{3}{*}{$10 \mathrm{~min}$} & 1 & No growth & 7 (92.3\%) \\
\hline & 2 & No growth & $3(96.7 \%)$ \\
\hline & 3 & No growth & 3 (96.7\%) \\
\hline \multirow[t]{3}{*}{$15 \min$} & 1 & No growth & No growth \\
\hline & 2 & No growth & No growth \\
\hline & 3 & No growth & No growth \\
\hline
\end{tabular}

${ }^{a}$ Number of CFU (percent reduction compared to controls)

reduction after a 10-min cycle, and no growth after a 15min cycle. For $C$. parapsilosis, there was a $90.2 \%$ reduction after a 5-min cycle, a $99.6 \%$ reduction after a 10 min cycle, and no growth after a 15 -min cycle.

The limitations of this study include a relative small study numbers and only one strain of $C$. auris. The strengths of this study include the inclusion of two common Candida species with varying distances from the PX-UV bulb. Previous studies have not tested the efficacy of PX-UV for Candida spp. Further studies are needed in hospital environment, to assess the cumulative impact of repeated sessions.

Candida auris and Candida parapsilosis are two pathogens commonly involved in outbreaks in healthcare settings outbreaks. They are often recovered from the hospital environment, where they can survive for a long time. Additional disinfection with hydrogen peroxide vapour is effective on $C$. auris and C. parapsilosis. However, this method is labour intensive as it requires sealing of the bed space, or doors and vents in case of a single-bed room, and monitoring of the concentration of $\mathrm{H}_{2} \mathrm{O}_{2}$ inside the enclosure before permitting patients or staff to enter into the room. The cycle time can last 2 to $8 \mathrm{~h}$ according to the $\mathrm{H}_{2} \mathrm{O}_{2}$ vapour system used. By comparison, the PX-UV technology, is easy to use and 
has significantly shorter cycle times that makes it easier to disinfect all areas outside the room where the patient received care, as recommended by the CDC.

\section{Conclusions}

We found a $99.6 \%$ reduction after a $10-$ min cycle at $2-\mathrm{m}$ distance, and a $95.2 \%$ reduction after a 10 -min cycle at 2-m distance. The PX-UV mobile device is easy to use and has short cycle times compared to other no-touch room disinfection technologies. Further studies are needed in hospital environment, to assess the cumulative impact of repeated sessions.

\section{Abbreviations}

C. auris: Candida auris; C. parapsilosis: Candida parapsilosis; CDC: Centre for Disease Control and prevention; CFUs: Colony-forming units; PBS: Phosphatebuffered saline; PX-UV: Pulsed-xenon ultraviolet; UV-C: Germicidal ultraviolet Light- C

\section{Acknowledgements}

The authors would like to thank Kiara Healthcare for the free access to the PX-UVD for the duration of the study.

\section{Authors' contributions}

$\mathrm{JC}$ conceived the methodology and supervised the process. MdP prepared and processed the cultures. CM did the statistical analysis and wrote the manuscript. All authors read and approved the final manuscript.

\section{Funding}

This work was supported by Ampath Laboratories. No external funding was received for this work.

\section{Availability of data and materials}

The datasets used and/or analysed during the current study are available

from the corresponding author on reasonable request.

Ethics approval and consent to participate

Not applicable, No patient involvement.

\section{Consent for publication}

Not applicable.

\section{Competing interests}

The authors declare that they have no competing interests.

\section{Author details}

'Department of Quality Leadership, Netcare Hospitals, Johannesburg, South Africa. ${ }^{2}$ Mycology Unit, Ampath National Reference Laboratory, Centurion, South Africa. ${ }^{3}$ Department of Clinical Microbiology and Molecular Biology, Ampath National Reference Laboratory, Centurion, South Africa.

Received: 8 March 2019 Accepted: 28 May 2019

Published online: 19 June 2019

\section{References}

1. Chowdhary A, Sharma C, Meis JF. Candida auris: a rapidly emerging cause of hospital-acquired multidrug-resistant fungal infections globally. PLoS Pathog. 2017;13(5):e1006290.

2. Sears D, Schwartz S. B. candida auris: An emerging multidrug-resistant pathogen. Int J Infect Dis. 2017;63:95-8.

3. Schelenz S, Hagen F, Rhodes JL, Abdolrasouli A, Chowdhary A, Hall A, Ryan L, Shackleton J, Trimlett R, Meis JF, Armstrong-James D, Fisher MC. First hospital outbreak of the globally emerging Candida auris in a European hospital. Antimicrob Resist Infect Control. 2016:5:35.

4. Bougnoux ME, Brun S, Zahar JR. Healthcare-associated fungal outbreaks: new and uncommon species, new molecular tools for investigation and prevention. Antimicrob Resist Infect Control. 2018;7:45,
5. Vallabhaneni S, Kallen A, Tsay S, Chow N, Welsh R, Kerins J, Kemble SK, Pacilli M, Black SR, Landon E, Ridgway J, Palmore TN, Zelzany A, Adams EH, Quinn M, Chaturvedi S, Greenko J, Fernandez R, Southwick K, Furuya EY, Calfee DP, Hamula C, Patel G, Barrett P, Lafaro P, Berkow EL, MoultonMeissner H, Noble-Wang J, Fagan RP, Jackson BR, Lockhart SR, Litvintseva AP, Chiller TM. Investigation of the first seven reported cases of Candida auris, a globally emerging invasive, multidrug-resistant fungus - United States, may 2013-august 2016. MMWR Morb Mortal Wkly Rep. 2016;65(44): 1234-7.

6. Piedrahita $C T$, Cadnum JL, Jencson AL, Shaikh AA, Ghannoum MA, Donskey CJ. Environmental surfaces in healthcare facilities are a potential source for transmission of Candida auris and other Candida species. Infect Control Hosp Epidemiol. 2017;38(9):1107-9.

7. Welsh RM, Bentz ML, Shams A, Houston H, Lyons A, Rose LJ, Litvintseva AP. Survival, persistence, and isolation of the emerging multidrug-resistant pathogenic yeast Candida auris on a plastic health care surface. J Clin Microbiol. 2017;55(10):2996-3005.

8. CDC. Candida auris interim recommendations for healthcare facilities and laboratories | Fungal diseases | CDC 2017 Available at: https:/www.cdc.gov/ fungal/diseases/candidiasis/recommendations.html.

9. Cadnum JL, Shaikh AA, Piedrahita CT, Jencson AL, Larkin EL, Ghannoum MA, Donskey CJ. Relative resistance of the emerging fungal Ppathogen Candida auris and other Candida species to killing by ultraviolet light. Infect Control Hosp Epidemiol. 2018;39(1):94-6.

10. Otter JA, Yezli S, Perl TM, Barbut F, French GL. The role of 'no-touch' automated room disinfection systems in infection prevention and control. J Hosp Infect. 2013;83(1):1-13.

\section{Publisher's Note}

Springer Nature remains neutral with regard to jurisdictional claims in published maps and institutional affiliations.

\section{Ready to submit your research? Choose BMC and benefit from:}

- fast, convenient online submission

- thorough peer review by experienced researchers in your field

- rapid publication on acceptance

- support for research data, including large and complex data types

- gold Open Access which fosters wider collaboration and increased citations

- maximum visibility for your research: over 100M website views per year

At BMC, research is always in progress.

Learn more biomedcentral.com/submissions 